\title{
PECULIARITIES OF DEEP IMPURITY RELATED CARRIER GENERATION IN CdTe AND GaAs CRYSTALS
}

\author{
A. Kadys, M. Sūdžius, and K. Jarašiūnas \\ Department of Semiconductor Optoelectronics, Institute of Materials Science and Applied Research, Vilnius University, \\ Sauletekio 9, LT-10222 Vilnius, Lithuania \\ E-mail: arunas.kadys@ff.vu.lt
}

Received 8 December 2003

\begin{abstract}
Degenerate four-wave mixing in GaAs:EL2 and CdTe:V at various modulation depths and intensities of light interference field has been carried out using $10 \mathrm{~ns}$ duration laser pulses at $1.06 \mu \mathrm{m}$ wavelength. We demonstrate a novel possibility of light diffraction technique, based on carrier generation by light interference pattern with different modulation depth $m$ and varying modulation intensity. Significant decrease of diffraction efficiency at the same modulation intensity but at different $m$ value was observed in exposure characteristics of light diffraction that is attributed to exhaustion of deep trap related carrier generation. This effect is found to be characteristic of the analysed photorefractive crystals and was not observed in $\mathrm{Si}$.
\end{abstract}

Keywords: four-wave mixing, deep states in semiconductors, numerical modelling

PACS: 71.55.-i, 78.20.Bh

\section{Introduction}

Characterization of deep levels in the semiconductors is very important because the levels can have profound effects on the optical and electrical properties of the semiconductor devices [1]. In semiinsulating compounds, the concentration of deep impurities as well as their compensation ratio may vary spatially, what can lead to bandgap modulation, enhanced carrier scattering, carrier spatial separation, thus limiting applications of these materials [2]. Investigation of growthrelated photoelectric properties is also important in understanding an origin of yellow-band luminescence in GaN [3] and compensation mechanism in semiinsulating $\mathrm{SiC}$ or InP [4-6]. Therefore, the development of optical techniques that are able to control homogeneity and compensation level in the semiinsulating materials is under demand.

In previous studies, the spatial modulation of nonequilibrium carrier density by a light interference field was used to create refractive index modulation and study free carrier dynamics with pico- or nanosecond resolution [7-9]. A number of peculiarities in carrier generation, diffusion, and recombination have been studied in semiinsulating photorefractive semiconductors. Monitoring the magnitude of grating diffraction efficiency allowed us to control distribution of neutral deep donor EL2 in a wafer of semiinsulating GaAs, however, the decay rate of free-carrier grating was found to be dependent on local density of ionized traps $[10,11]$. The transport of nonequilibrium carriers excited from deep traps was found to be strongly affected by light-induced space charge field $[8,12]$. Screening of the field by high carrier density resulted in a change of the effective diffusion coefficient, and this effect was used as a criterion to distinguish the type of photogenerated carriers in vanadium-doped CdTe [12]. In the nanosecond time scale, when carrier generation, diffusion, and recombination take place during the action of a laser pulse, the time-integrated diffracted beam revealed mainly peculiarities related to carrier generation rate from deep EL2 traps as well as their temporary transfer to a metastable state at room temperature. They have been used to map dislocation density in GaAs wafers $[11,13]$ and monitor the rate of thermal recovery of EL2 from its metastable state $[9,14,15]$.

In this paper we extend the application of nonlinear four-wave mixing technique for characterization of deep levels in bulk crystals. We show that variation of modulation depth and intensity of light interference field leads to various carrier generation rates from or via deep traps. The exhaustion of deep traps at certain optical flux densities is varying spatially along a grating period and can be sensitively used by the transient 
grating technique. Therefore, variation of modulation depth and intensity of interference field provides a simple way to characterize carrier generation mechanisms.

\section{Numerical modelling}

We solve numerically a set of rate equations coupled with the equation for the light interference pattern $I(x)=\left(I_{01}+I_{02}\right)[1+m \cos (K x)]$, where $K=2 \pi / \Lambda$ is the grating vector, $I_{01}$ and $I_{02}$ are intensities of the interfering beams, and $m$ is the modulation depth of light interference pattern, $m=$ $2 \sqrt{I_{01} / I_{02}} /\left[1+\left(I_{01} / I_{02}\right)\right]$. Thus, the modulation intensity of the interference pattern as well as the nonmodulated part can be varied by changing intensity ratio of interfering beams.

Carrier generation, diffusion, and recombination are described by the following material equations $[8,16]$, which also account for carrier drift in the space-charge field:

$$
\begin{aligned}
\frac{\partial N_{\mathrm{e}}}{\partial t}= & \frac{S_{\mathrm{e}} I N^{0}}{h \nu}+\frac{\beta I^{2}}{2 h \nu}+\frac{1}{e} \frac{\partial j_{\mathrm{e}}}{\partial x} \\
& -\gamma_{\mathrm{e}} N_{\mathrm{e}} N^{+}-\gamma_{\mathrm{eh}} N_{\mathrm{e}} N_{\mathrm{h}}, \\
\frac{\partial N_{\mathrm{h}}}{\partial t}= & \frac{S_{\mathrm{h}} I N^{+}}{h \nu}+\frac{\beta I^{2}}{2 h \nu}-\frac{1}{e} \frac{\partial j_{\mathrm{h}}}{\partial x} \\
& -\gamma_{\mathrm{h}} N_{\mathrm{h}} N^{0}-\gamma_{\mathrm{eh}} N_{\mathrm{e}} N_{\mathrm{h}}, \\
\frac{\partial N^{+}}{\partial t}= & \frac{S_{\mathrm{e}} I N^{0}}{h \nu}-\frac{S_{\mathrm{h}} I N^{+}}{h \nu} \\
& -\gamma_{\mathrm{e}} N_{\mathrm{e}} N^{+}+\gamma_{\mathrm{h}} N_{\mathrm{h}} N^{0}, \\
j_{\mathrm{e}}= & e N_{\mathrm{e}} \mu_{\mathrm{e}} E_{\mathrm{SC}}+\mu_{\mathrm{e}} k_{\mathrm{B}} T \frac{\partial N_{\mathrm{e}}}{\partial x}, \\
j_{\mathrm{h}}= & e N_{\mathrm{h}} \mu_{\mathrm{h}} E_{\mathrm{SC}}-\mu_{\mathrm{h}} k_{\mathrm{B}} T \frac{\partial N_{\mathrm{h}}}{\partial x}, \\
\frac{\partial E_{\mathrm{SC}}}{\partial x}= & -\frac{e}{\varepsilon_{0} \varepsilon_{r}}\left(N_{\mathrm{e}}+N_{\mathrm{A}}-N_{\mathrm{h}}-N^{+}\right) .
\end{aligned}
$$

Here, generation of electron $N_{\mathrm{e}}$ and hole $N_{\mathrm{h}}$ densities from deep traps is given by Eqs. (1) and (2), while the density of deep impurity $N^{+}$in the ionized state is described by Eq. (3). $N^{0}$ in these equations stands for the deep trap density in the neutral state. Carrier diffusion from the grating peaks creates an internal electric field $E_{\mathrm{SC}}$ (Eq. (6)), in which the electrons and holes are drifting, Eqs. (4) and (5). Carrier generation at low excitations depends on parameters $S_{\mathrm{e}}$ and $S_{\mathrm{h}}$, which represent the photoionization cross-sections. At high incident powers the two-photon absorption may take place with the coefficient $\beta$. Carrier recombination is described by their trapping with coefficients $\gamma_{\mathrm{e}}$ and $\gamma_{\mathrm{h}}$, while at high carrier densities, by bimolecular recombination with the coefficient $\gamma_{\mathrm{eh}}$. Electron (hole) mobility is denoted as $\mu_{\mathrm{e}}\left(\mu_{\mathrm{h}}\right), N_{\mathrm{A}}$ stands for the concentration of acceptors, $\varepsilon_{0} \varepsilon_{r}$ is the permittivity of the material, $k_{\mathrm{B}}$ is the Boltzmann constant, and $T$ is the absolute temperature of the sample.

Using Eqs. (1)-(6), we have calculated numerically spatial distribution of electrons, holes, ionized donors, and their temporal dynamics. We assumed typical density of deep donors, $N_{\mathrm{T}}=1 \cdot 10^{16} \mathrm{~cm}^{-3}$ for GaAs [17] and CdTe [8], which are totally filled by the electrons in the dark, i. e. $N_{\mathrm{A}} / N_{\mathrm{T}}=\left.N^{+}\right|_{\text {dark }} / N_{\mathrm{T}}$. We analysed the case of carrier generation by $15 \mathrm{~ns}$ duration laser pulses at the $1.064 \mu \mathrm{m}$ wavelength. The grating period was $10 \mu \mathrm{m}$ in all calculations (see [8] for the material parameters).

The calculated spatial density distribution of electrons and ionized deep impurity at three excitation intensities is presented in Fig. 1. We do not present spatial density profiles for the holes, as their contribution to refractive index modulation is smaller by a factor of $m_{\mathrm{e}} / m_{\mathrm{h}}$ [9]. In addition, the density of photoexcited holes is smaller than that of electrons because of their smaller photoionization cross-section, $S_{\mathrm{h}} \ll S_{\mathrm{e}}[8,9]$.

At low intensities, when the number of photons is less than the concentration of neutral traps $N^{0}$, the linear carrier generation from deep traps takes place $\left(S_{\mathrm{e}} N^{0} \gg S_{\mathrm{h}} N^{+}\right)$. Therefore, the density profiles for both electrons and ionized traps are sinusoidal and weakly depend on the modulation depth $m$ (Fig. 1(a,d)). At higher energies, photoionization of deep donors saturates in the vicinity of the grating peaks [9]. Thus, the absorption partially saturates (Fig. 1(e)), causing the decrease of electron generation rate as well (Fig. 1(b)). It is important to note that the effect of saturation is more pronounced for $m<1$, when the carriers are generated both in grating maxima and minima, because for $m=1$, the saturation of absorption in grating minima is never achieved. At even higher excitation (Fig. 1(c, f)), the carrier generation via deep traps (two-step transitions) as well as twophoton absorption (which does not require real mid-gap impurity state) contribute to carrier generation, and as a result, the electron spatial profile again becomes sinusoidal (Fig. 1(c)), while the density profile for ionized traps exhibits complete saturation (Fig. 1(f)). 


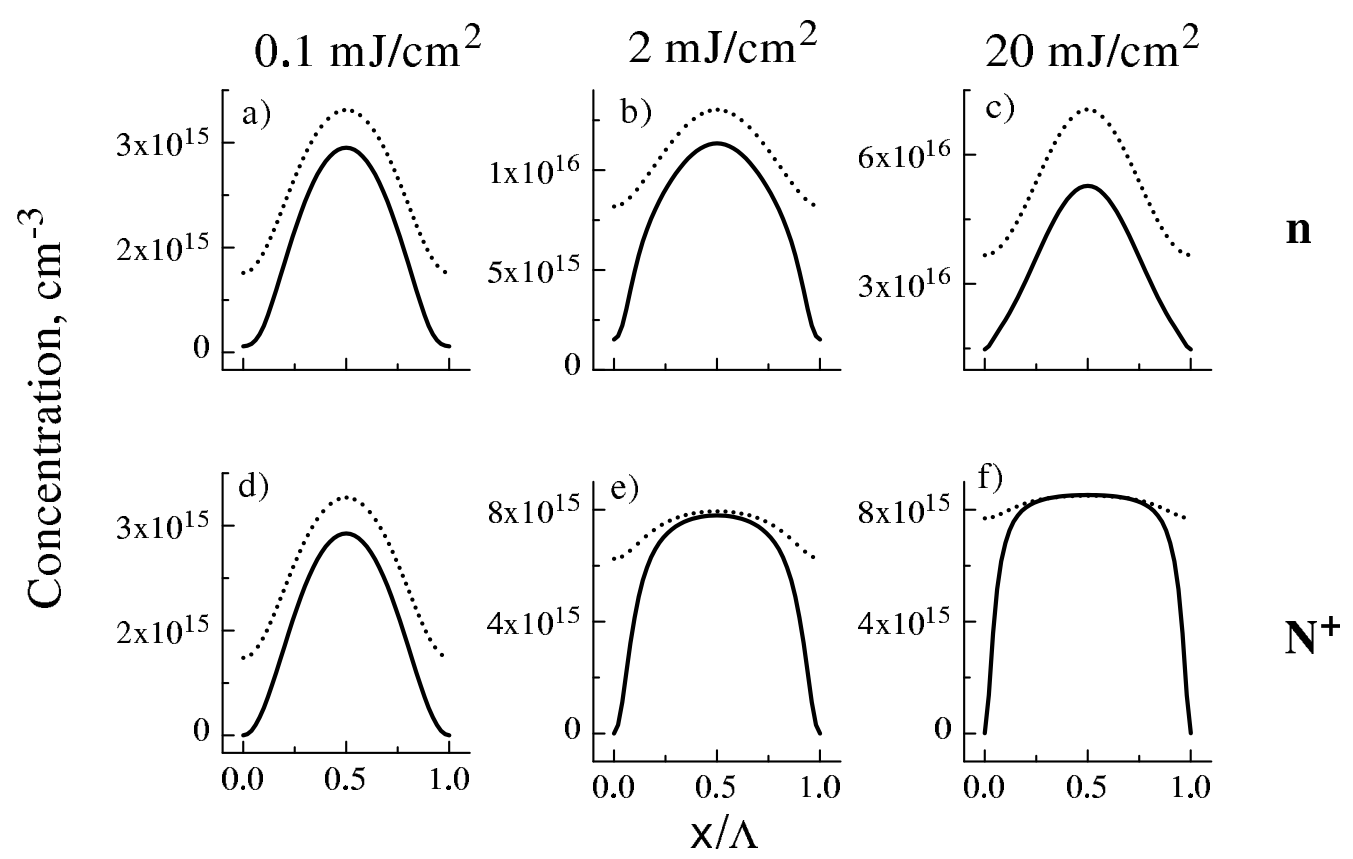

Fig. 1. Calculated density profiles of (a, b, c) electrons and (d, e, f) ionized donors at two modulation depths $m$ of the interference field: solid line, $m=1$; dotted line, $m=0.63$. The density profiles are shown for modulating intensities $I_{\text {mod }}=0.1,2$, and $20 \mathrm{~mJ} / \mathrm{cm}^{2}$. The total excitation density can be obtained from the relationship $I_{0}=I_{\bmod } / \mathrm{m}$.

Considering the absorption mechanisms described by Eqs. (1)-(6), the absorption is given by $\alpha \approx$ $S_{\mathrm{e}}\left(N_{\mathrm{T}}-N^{+}\right)+S_{\mathrm{h}} N^{+}+\beta I$. Spatial modulation of absorption coefficient gives rise to an absorption grating formation with absorption index modulation $\Delta k=\Delta \alpha \lambda /(4 \pi)$. Thus, $\Delta k$ variation follows the evolution of charge density gratings and vanishes as soon as the spatial charge distribution becomes uniform. It was shown, however, both numerically [9] and experimentally [15] that in the case of the typical trap density of $\sim 10^{16} \mathrm{~cm}^{-3}$ the contribution of absorption grating is negligible with respect to free carrier nonlinearity.

The calculated spatial profiles were used to simulate dependence of diffraction efficiency on excitation intensity, or so-called exposure characteristic (EC) of diffraction $[18,19]$. The latter dependence is a power function versus excitation, $\eta=I_{1} / I_{\mathrm{T}} \propto I_{\text {mod }}^{\gamma}$. Plotted in the $\log -\log$ scale, it provides a power index $\gamma=\Delta \log (\eta) / \Delta \log \left(I_{\text {mod }}\right)$, which describes the rate of diffraction efficiency increase with excitation and strongly correlates with carrier generation rate. For example, for linear carrier generation, $N \propto \alpha I_{0}$, the diffraction efficiency increases quadratically with excitation $I_{0}$, according to relationship $\eta \propto \Delta N^{2} \propto I_{0}^{2}$.

In Fig. 2 we plotted the calculated exposure characteristics at two time moments, which correspond to diffraction of probe beam, which was "delayed" by $-5 \mathrm{~ns}$ or $5 \mathrm{~ns}$ with respect to the peak of a laser pulse, i. e. the grating was probed during its build-up or after the main part of $15 \mathrm{~ns}$ duration laser pulse was over. The diffraction efficiency is shown as a function of modulating intensity $I_{\text {mod }}=2 m I_{0}$ rather than just of $I_{0}$, since only the first Fourier component of the Bragg grating gives an origin to diffraction [20]. In this way, comparison of exposure characteristics, which were measured at different $m$ values, reveals the impact of nonmodulated part of the interference field.

The saturation of absorption at $I_{0}=1 \mathrm{~mJ} / \mathrm{cm}^{2}$ (Fig. 2(a)) is evident from the change of slope value, from $\gamma=2$ to 0.5 , and is more pronounced for smaller $m$ values. At later time (Fig. 2(b)), the similar slope values are seen at lower energies. This is a consequence of longer exposure of deep traps by light, therefore, absorption saturates at significantly lower excitation. With increasing excitation up to $10 \mathrm{~mJ} / \mathrm{cm}^{2}$, twostep transitions increase the carrier generation rate to the value of $\gamma=1.8$.

A higher sensitivity of light diffraction to deep trap exhaustion in the case when $m<1$ can be explained as follows. The light interference field with modulation depth $m<1$ has a nonmodulated background $I_{\min }$, which excites carriers homogeneously along the grating vector. It leads to homogeneous density of photoionized levels, which assist in light absorption, thus, it becomes easier to saturate the deep trap related absorption of the modulated part of light interference pat- 


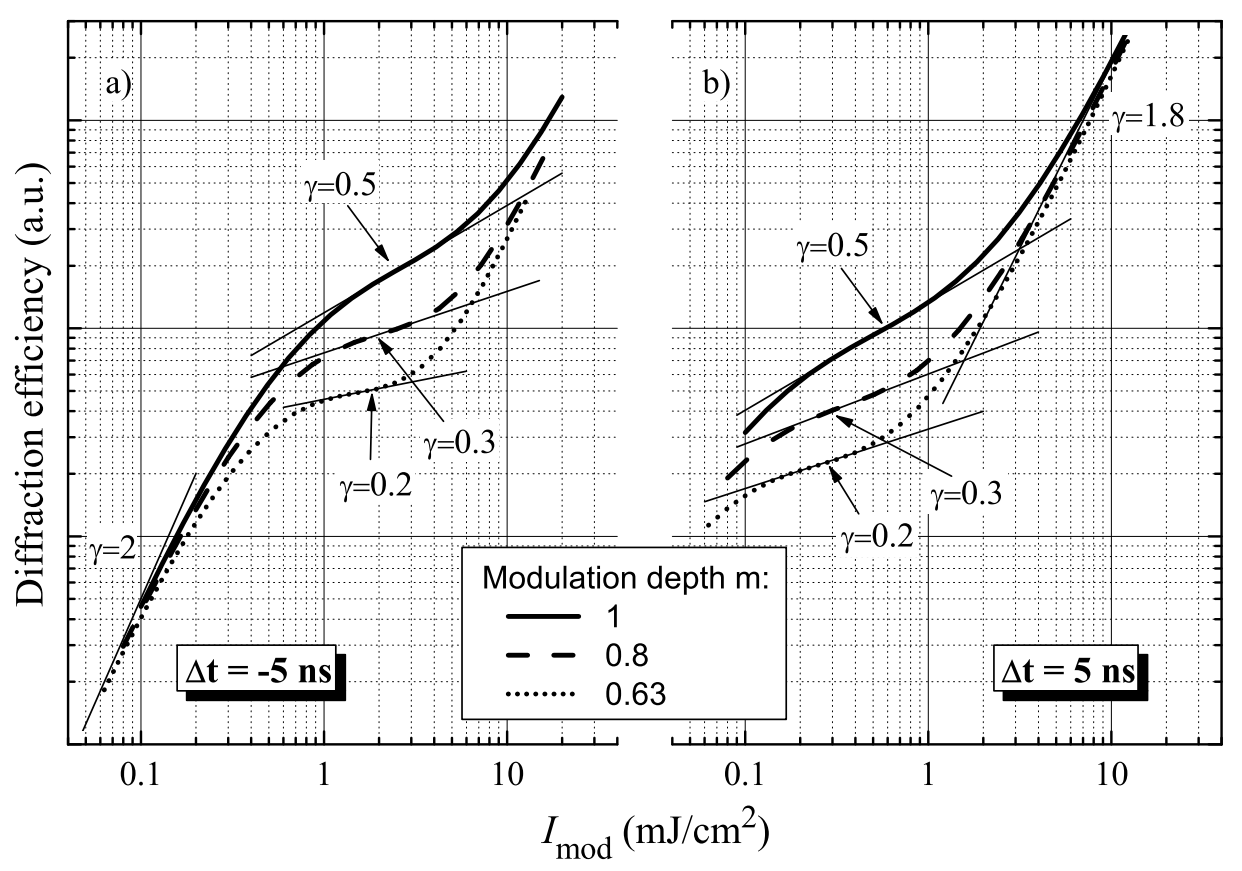

Fig. 2. Instantaneous diffraction efficiency as a function of modulating excitation density shown for three modulation depth values $m$ of the interference field. The results are shown at two different moments $\Delta t$ with respect to the peak intensity of the laser beam.

tern. The lower is $m$ value, the higher is intensity of nonmodulated background and more pronounced saturation of the traps follows. The calculations predict that a crystal with the totally filled deep traps is most sensitive to trap saturation, since the photoionization cross-section for the electrons $S_{\mathrm{e}}$ is larger than that for holes $S_{\mathrm{h}}$. On the other hand, in a crystal with totally ionized deep traps, two-step transitions dominate in all the range of excitations, thus, diffraction does not exhibit the tendency of decreased $\gamma$ value.

\section{Samples and experimental technique}

Two experimentally investigated bulk crystals, GaAs and vanadium-doped/Cl-codoped $\mathrm{CdTe}$, present the characteristic semiconductors with deep traps, where the native defect EL2 or vanadium serve as a deep midgap donors $[8,21,22]$. The GaAs sample was cut from the central part of 3 inch wafer and had resistivity of $\rho=5 \cdot 10^{6} \Omega \cdot \mathrm{cm}$ and dislocation density of $N_{\mathrm{D}} \approx 3 \cdot 10^{4} \mathrm{~cm}^{-2}$. The total density of deep centres, located at position $E_{\mathrm{c}}=-0.9 \mathrm{eV}$, was about $N_{\mathrm{T}} \approx 3 \cdot 10^{16} \mathrm{~cm}^{-3}$. Previous studies of these crystals have shown strong variation of EL2 density and compensation ratio in the wafer $[11,13]$. Consequently, the dark state compensation ratio for this particular crystal is not well known. The charge state of vanadium in the CdTe: $V$ crystal was modified by codoping with a shallow donor $\mathrm{Cl}$. Therefore, for this particular sample, the vanadium trap is totally filled by electrons [8]. The density of vanadium, determined by SIMS technique, was equal to $3.2 \cdot 10^{15} \mathrm{~cm}^{-3}$.

For comparison, we measured exposure characteristics of light diffraction in the Si crystal, in which interband carrier generation coefficient $\alpha \approx 10 \mathrm{~cm}^{-1}$ at $300 \mathrm{~K}$ solely determines the bipolar carrier generation rate at the $1.064 \mu \mathrm{m}$ wavelength, thus, no effect of the deep traps is expected.

An experimental setup for transient grating measurements is shown schematically in Fig. 3. A Q-switched YAG-laser operating at $4 \mathrm{~Hz}$ repetition rate provides $12 \mathrm{~ns}$ duration pulses at $1.064 \mu \mathrm{m}$ wavelength. The grating is excited by two s-polarized beams $I_{01}$ and $I_{02}$ which create an interference pattern with $\Lambda=$ $\lambda /[2 \sin (\theta / 2)]$ spacing. Here $\lambda$ is the pump wavelength and $\theta$ is an intersection angle of the writing beams. As a beam splitter, we use Glan prism G2; hence, the intensity ratio of the writing beams $I_{01} / I_{02}$ (and consequently the modulation depth of the interference pattern) can be varied by half-wave plate L2 which defines the polarization state of the incoming laser beam. The p-polarized probe beam $I_{\mathrm{P}}$ is counterpropagating to the $I_{01}$ beam. The probe beam intensity was roughly one order of magnitude weaker then the total intensity $I_{0}$. Therefore, it can be assumed that the probe beam changes neither the charge state of the deep trap, nor the spatial distribution of photocarriers. The total 


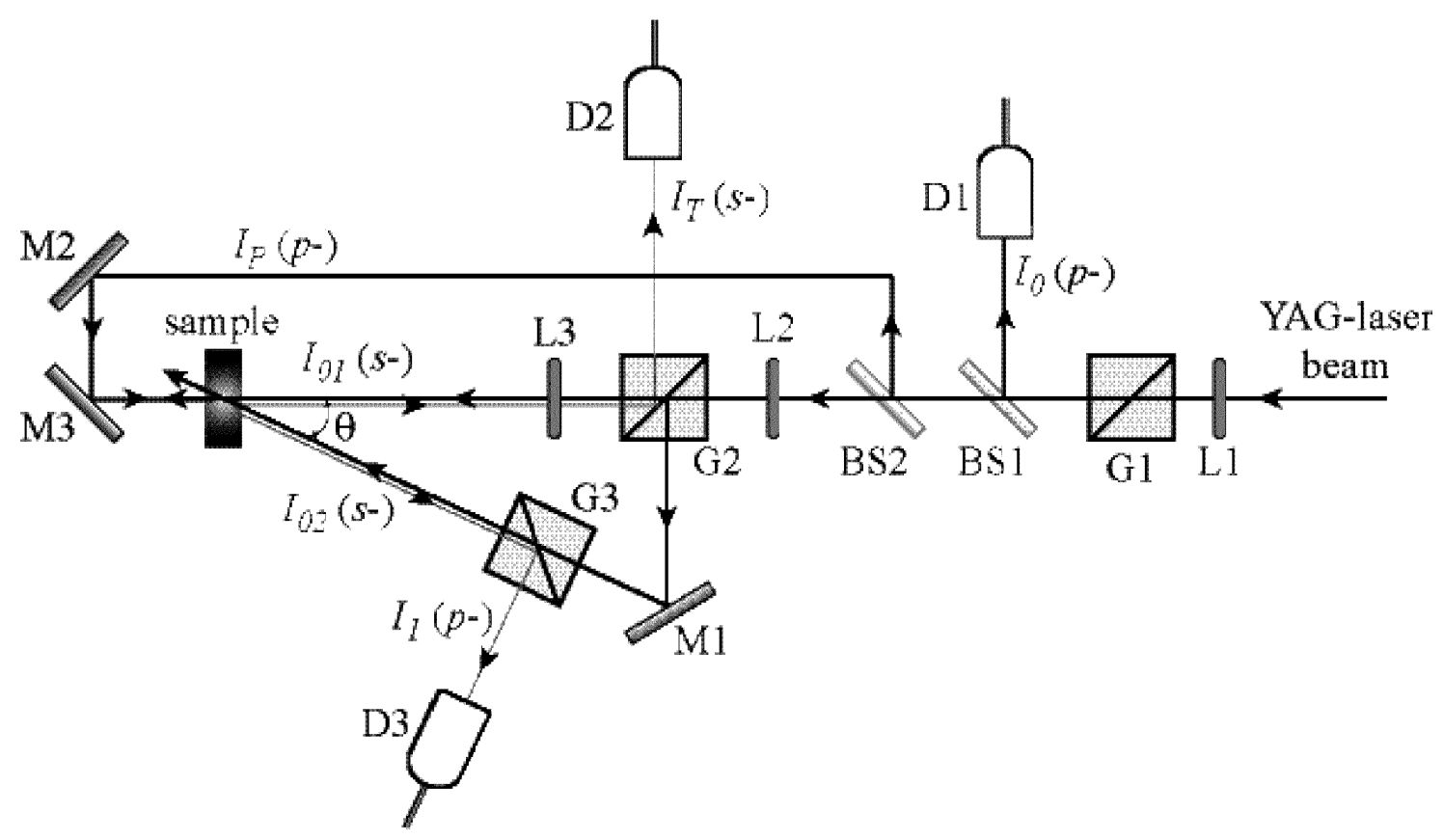

Fig. 3. Arrangement for the DFWM experiments. The elements shown are: dielectric mirrors M1-3; beam splitters BS1-2; half-wave plates L1-3; Glan prisms G1-3; Si photodetectors D1-3.

intensity of the writing beams, $I_{0}=I_{01}+I_{02}$, can be changed by an attenuator L1-G1.

The diffracted p-polarized wave $I_{1}$ travels at the Bragg-matched angle (and counterpropagates $I_{02}$ beam) until it is extracted by a Glan prism G3. The transmitted p-polarized probe beam $I_{\mathrm{T}}$ counterpropagates to $I_{01}$ beam and is extracted by a Glan prism G2 after its polarization is changed to s-polarization by a half-wave plate L3. We note that such a scheme allows extraction of nearly $100 \%$ of the transmitted and diffracted beams. Intensities of $I_{0}, I_{\mathrm{T}}$, and $I_{1}$ beams are measured, respectively, by Si photodiodes D1, D2, and D3, and memorized in the data acquisition system.

The scheme shown in Fig. 3 is ideally suitable for the experiments where the modulation depth $m$ of the interference field has to be varied with overall optical flux fixed to some constant value, since the beam splitter L2-G2-L3 does not introduce any loss in the total energy. In this work, however, we present only the exposure characteristics of diffraction efficiency measured at various modulation depths $m$ of the interference field.

\section{Results and discussion}

As demonstrated by the numerical modelling, the modulation depth of the interference field plays a crucial role in the spatial distribution of free carriers, as- suming that they are excited from deep traps and the excitation level is on the threshold of deep trap exhaustion. We use this feature to distinguish between generation mechanisms in different crystals as well as to characterize deep traps in case they are dominant in free carrier generation. In Fig. 4, we show EC of time-integrated diffraction efficiency measured in GaAs:EL2 (Fig. 4(a)), CdTe:V (Fig. 4(b)), and Si (Fig. 4(c)) crystals at various modulation depths of the interference field. The total intensity of the recording beams varied in the range from 2 up to $50 \mathrm{~mJ} / \mathrm{cm}^{2}$. The grating with $10 \mu \mathrm{m}$ period was probed by a beam delayed about 2 ns. The diffraction efficiency was calculated as the ratio of the measured intensities $\eta=I_{1} / I_{\mathrm{T}}$.

For GaAs:EL2 and CdTe:V crystals (Fig. 4(a,b)), an increase of diffraction efficiency with $m$ for certain $I_{\text {mod }}$ values confirms that the photocarriers, which dominate in free carrier optical nonlinearity, are generated optically from the deep traps. According to the well-known equation for diffraction efficiency [20], $\eta \approx\left(\pi n_{\mathrm{eh}} \Delta N_{\text {eff }} d / \lambda\right)^{2}$, we calculated the effective concentration of carrier modulation $\Delta N_{\text {eff }}$ using the experimentally measured $\eta$ values. For GaAs:EL2 and CdTe:V crystals, $\Delta N_{\text {eff }} \approx 10^{16} \mathrm{~cm}^{-3}(m=1$, $I_{\text {mod }}=10 \mathrm{~mJ} / \mathrm{cm}^{2}$ ), which is close to the typical concentration of deep traps in these materials $[8,9]$. Thus, the process of absorption saturation from the deep traps 


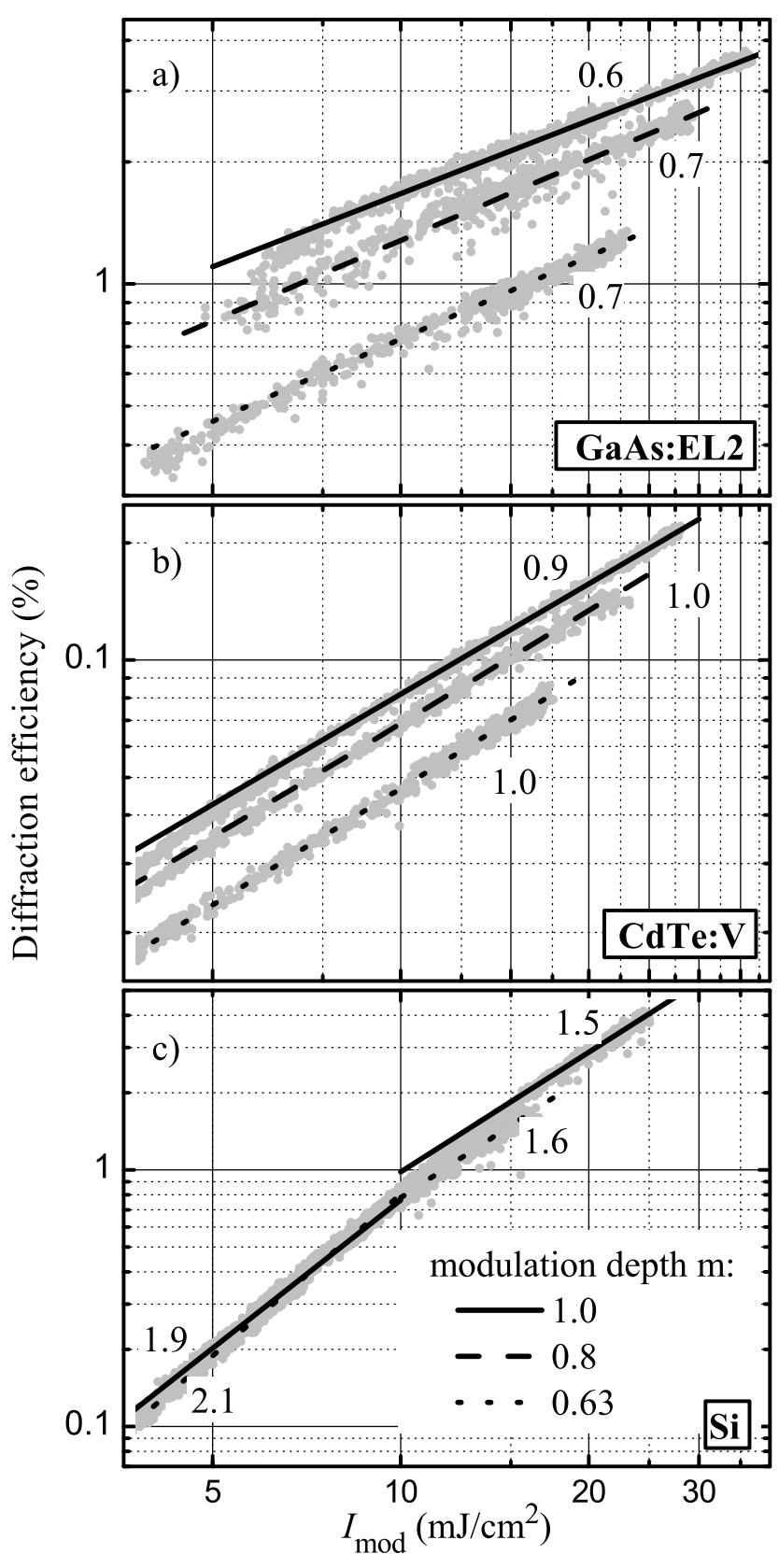

Fig. 4. Exposure characteristics of diffraction efficiency measured at three modulation depths $m$ of the interference field in (a) GaAs:EL2, (b) CdTe:V, and (c) Si bulk crystals. Lines show characteristic slopes of EC.

takes place and gives rise to sublinear slopes of EC $(\gamma=0.6-1<2$ in Fig. 4(a,b)). Conversely, the analogous measurements in $\mathrm{Si}$ (Fig. 4(c)) did not reveal any dependence on $m$, since no exhaustion of band states is expected for interband transitions. Moreover, the slope of EC, $\gamma \approx 2$ for $I_{\text {mod }}<10 \mathrm{~mJ} / \mathrm{cm}^{2}$, confirms carrier generation mechanism by one-photon process, i.e. $\eta \propto \Delta N_{\text {eff }}^{2} \approx\left(\alpha I_{\text {mod }}\right)^{2}$. Further decrease of the slope with excitation can be attributed to the intraband free-carrier absorption in $\mathrm{Si}$ [23], as the diffraction efficiency of $1 \%$ at $10 \mathrm{~mJ} / \mathrm{cm}^{2}$ corresponds to $\Delta N_{\text {eff }} \approx 1 \cdot 10^{17} \mathrm{~cm}^{-3}$ for a $300 \mu \mathrm{m}$ thick Si wafer.

Although in our experiments the modulating intensity of the interference pattern varied within the large range of intensities, the change of EC slope with $m$ has not been observed. Particularly, for lower values of $m$ ( 0.8 and 0.63$)$, the slope of EC has not decreased, as it was predicted by numerical calculations (see Fig. 2), but remained nearly the same in all range of excitations. The possible reason for this might be quite long duration of the laser pulse during which the local generation/recombination rates as well as drift/diffusion of nonequilibrium carriers may vary significantly with time [9]. Indeed, numerical analysis has shown that the instantaneous slopes at fixed energy of $2 \mathrm{~mJ} / \mathrm{cm}^{2}$ may change from 0.5 to higher slope values with time (see Fig. 2). The long laser pulse duration is also unfavourable to reveal nonlinear two-step and two-photon mechanisms of carrier generation. Therefore, we believe that timeresolved FWM with picosecond duration pulses should demonstrate higher sensitivity to variation of $m$. In the latter case, the processes of carrier generation might be separated from subsequent carrier diffusion and recombination by varying the delay time of the probe beam and grating period. These studies are in progress.

\section{Conclusions}

Degenerate four-wave mixing in GaAs:EL2, CdTe:V, and $\mathrm{Si}$ crystals at various modulation depths of light interference pattern has been carried out using $10 \mathrm{~ns}$ duration laser pulses at the $1.06 \mu \mathrm{m}$ wavelength. Significant decrease of diffraction efficiency with decreasing modulation depth of the interference field, while preserving the same intensity of the modulated part of the interference field, has been attributed to exhaustion of a deep trap assisted carrier generation channel. The effect is characteristic of photorefractive crystals and, therefore, has not been observed in Si where interband carrier generation takes place. Nanosecond duration of the laser pulse competed with carrier recombination and diffusion processes and did not allow us to reveal the changes of modulation depth dependent carrier generation rate. Degenerate four wave mixing using the picosecond duration pulses is expected to be more favourable case for 
studies of modulation depth dependent deep trap exhaustion.

\section{Acknowledgements}

The research was sponsored by NATO Scientific Affairs Division in the framework of the Science for Peace Programme (Project SfP-974476), European Commission (Contract No. G5MA-CT-2002-04047), and Lithuanian State Science and Education Foundation.

\section{References}

[1] E. Garmire and A. Kost (eds.), Nonlinear Optics in Semiconductors, Vols. 1-2, Semiconductors and Semimetals, Vol. 59 (Academic Press, 1999).

[2] V. Kažukauskas, J. Storasta, and J.V. Vaitkus, Interaction of deep levels and potential fluctuations in scattering and recombination phenomena in semi-insulating GaAs, J. Appl. Phys. 80, 2269-2277 (1996).

[3] I. Shalish, L. Kronik, C. Segal, Y. Rosenwaks, Y. Shapira, U. Tisch, and J. Salzman, Yellow luminescence and related deep levels in unintentionally doped GaN films, Phys. Rev. B 59(15), 9748-9751 (1999).

[4] J.R. Jenny, M. Skowronski, W.C. Mitchel, H.M. Hobgood, R.C. Glass, G. Augustine, and R.H. Hopkins, On the compensation mechanism in high-resistivity $6 \mathrm{H}-\mathrm{SiC}$ doped with vanadium, J. Appl. Phys. 78(6), 3839-3842 (1995).

[5] A. Edwards, D.N. Dwight, M.V. Rao, M.C. Ridgway, G. Kelner, and N. Papanicolaou, Compensation implants in 6H-SiC, J. Appl. Phys. 82(9), 4223-4227 (1997).

[6] Y.W. Zhao, Y.L. Luo, S. Fung, C.D. Beling, N.F. Sun, X.D. Chen, L.X. Cao, T.N. Sun, K.Y. Bi, and X. Wu, Native donors and compensation in $\mathrm{Fe}$-doped liquid encapsulated Czochralski InP, J. Appl. Phys. 89(1), 86-90 (2001).

[7] K. Jarasiunas, J. Vaitkus, P. Delaye, and G. Roosen, Dislocation density-dependent photorefractive effect in (001)-cut GaAs, Opt. Lett. 19(23), 1946-1948 (1994).

[8] K. Jarasiunas, L. Bastiene, J.C. Launay, P. Delaye, and G. Roosen, Role of the charge state of deep vanadium impurities and associations of defects in photoelectric and optical properties of semi-insulating CdTe, Semicond. Sci. Technol. 14(1), 48-57 (1999).

[9] M. Sudzius, A. Bastys, and K. Jarasiunas, Optical nonlinearities at transient quenching of EL2 defect at room temperature, Opt. Commun. 170(1-3), 149-160 (1999).
[10] K. Jarasiunas and N. Lovergine, Characterisation of bulk crystals and structures by light-induced transient grating technique, Mat. Sci. Eng. B 91, 100-104 (2002).

[11] M. Sūdžius, V. Gudelis, R. Aleksiejūnas, J. Storasta, K. Jarašiūnas, and A. Cola, in: Selected Papers on Optics and Photonics: Optical Diagnostics of Materials and Devices for Opto-, Micro-, and Quantum Electronics, Proc. SPIE, Vol. 5024, eds. S.V. Svechnikov and M.Ya. Valakh (SPIE, Washington, 2003) pp. $145-156$.

[12] M. Sūdžius, R. Aleksiejūnas, K. Jarašiūnas, D. Verstraeten, and J.C. Launay, Investigation of nonequilibrium carrier transport in vanadium-doped CdTe and $\mathrm{CdZnTe}$ crystals using the time-resolved four-wave mixing technique, Semicond. Sci. Technol. 18, 367376 (2003).

[13] J. Vaitkus, E. Gaubas, K. Jarasiunas, and M. Petrauskas, Mapping of GaAs and $\mathrm{Si}$ wafers and ionimplanted layers by light-induced scattering and absorption of IR light, Semicond. Sci. Technol. 7(1A), A131-A134 (1992).

[14] M. Sūdžius, K. Jarašiūnas, and A. Bastys, Optical nonlinearities at deep-donor metastable transformation in GaAs, Lithuanian J. Phys. 40(1-3), 194-200 (2000).

[15] R. Aleksiejunas, M. Sudzius, and K. Jarasiunas, Direct determination of EL2 thermal recovery rate at $300 \mathrm{~K}$, Opt. Commun. 198(1-3), 115-120 (2001).

[16] A.L. Smirl, G.C. Valley, K.M. Bohnert, and T.F. Bogges, Jr., Picosecond photorefractive and free-carrier transient energy transfer in GaAs at $1 \mu \mathrm{m}$, IEEE J. Quantum Electron. 24, 289-303 (1988).

[17] C.G. Kirkpatrick, R.T. Chen, D.E. Holmes, P.M. Asbeck, K.R. Elliott, R.D. Fairman, and J.R. Oliver, in: Semiconductors and Semimetals, eds. R.K. Willardson and A.C. Beer (Academic Press, 1984) pp. 159-231.

[18] R.K. Jain and M.B. Klein, in: Optical Phase Conjugation, ed. R.A. Fischer (Academic Press, 1983), pp. 307-415.

[19] D.W. Fischer, Photon-induced recovery of photoquenched EL2 intracenter absorption in GaAs, Appl. Phys. Lett. 50, 1751-1753 (1987).

[20] H.J. Eichler, P. Günter, and D.W. Pohl, LaserInduced Dynamic Gratings (Springer, Berlin/Heidelberg, 1986).

[21] J.C. Bourgoin, H.J. von Bardeleben, and D. Stiévenard, Native defects in gallium arsenide, J. Appl. Phys. 64, R65-R91 (1988).

[22] J. Dabrowski and M. Scheffler, Isolated arsenic-antisite defect in GaAs and the properties of EL2, Phys. Rev. B 40, 10391-10401 (1989).

[23] H.J. Eichler and F. Massmann, Diffraction efficiency and decay times of free-carrier gratings in silicon, J. Appl. Phys. 53, 3237-3242 (1982). 


\title{
GILIŲ LYGMENŲ ITAKOTI KRŪVININKŲ GENERACIJOS YPATUMAI CdTe IR GaAs KRISTALUOSE
}

\author{
A. Kadys, M. Sūdžius, K. Jarašiūnas \\ Vilniaus universitetas, Vilnius, Lietuva
}

\section{Santrauka}

Naudojant išsigimusio keturių bangų maišymo metodiką, buvo tyrinèti CdTe:V ir GaAs:EL2 tūriniai kristalai, gardelès sužadinimui ir jos nuskaitymui panaudojant $10 \mathrm{~ns}$ trukmès ir $1064 \mathrm{~nm}$ bangos ilgio lazerio šviesos impulsus. Iš rezultatų matyti, kad fotorefraktyviuose kristaluose difrakcijos efektyvumas labai priklauso nuo interferencinio lauko moduliacijos kokybės: išlaikant pastovų moduliuojantį žadinimo intensyvumą, difrakcijos efekty- vumas mažeja, mažějant moduliacijos gyliui $m$. Tuo tarpu ši priklausomybė Si kristale nebuvo pastebèta. Pasitelkus skaitmenini modeliavima, parodyta, kad, vykstant efektyviam generacijos centrų perelektrinimui šviesa, difrakcijos efektyvumo sumažejimas, mažejant interferencinio lauko moduliacijos gyliui, priklauso nuo generacijos kanalo išsekinimo. Ši efektą apibūdina ne tik difrakcijos efektyvumo, bet ir ekspozicinès kreivès polinkio sumažejimas. 